\title{
Grounded Theory in Second/Foreign Language Education Research
}

\author{
Muhlisin Rasuki ${ }^{1}$ \\ ${ }^{1}$ Universitas Muhammadiyah Jember, Indonesia \\ (muhlisin@unmuhjember.ac.id)
}

\begin{abstract}
Grounded theory constitutes research methodology commonly used in the field of social sciences to investigate social phenomena. This research methodology, however, has rarely been used in the field of second/foreign language education. Given that second/foreign language education may be viewed as a social activity and certain issues in second/foreign language education may be studied from social science perspectives, the present article surveys key literature on grounded theory. The goal is to help second/foreign language researchers assess the potential of this research methodology and, where applicable, employ this methodology for studying relevant issues in the field of second/foreign language education. After a brief introduction, the article offers a historical review of grounded theory to provide a context for understanding of what grounded theory is and how it has evolved into distinct methodological designs. The philosophical paradigms underlying grounded theory are then described, and information of how those paradigms typically guide research practices in the field of social sciences is presented. Finally, criticisms that have been levelled against grounded theory are outlined so that $\mathrm{L} 2$ researchers are aware of any limitations of this research methodology and, if possible, find a way to cope with those limitations when employing grounded theory in their studies. The article concludes with an argument that despite those limitations, L2 researchers should not feel reluctant to employ this research methodology in their studies, especially when the research problem is best approached through employing this research methodology.
\end{abstract}

Keywords: second/foreign language (L2) education; grounded theory; research methodology.

Grounded theory is one of prominent research methodologies in the field of social sciences (Clark et al., 2021, p. 526). As research methodology, grounded theory may be seen as systematic attempts to generate a theory that can help explain social phenomena. Given that second/foreign language (L2) education may be seen as social activity and certain issues in the field of L2 education may be viewed from social science perspectives (Hornberger \& McKay, 2010), the present article surveys key literature on grounded theory to help L2

How to cite (in APA style):

Rasuki, M. (2021). Grounded Theory in Second/Foreign

Language Education Research. English Language, Literature, and

Teaching, 6(2), 78-84 doi: 10.32528/ellite.v6i2.6099 
researchers assess the potential of this research methodology and, where applicable, employ this methodology for studying relevant issues in the field of L2 education.

This article begins with a brief historical review of grounded theory to provide a context for understanding of what grounded theory is and how it has evolved into distinct methodological designs since its first formulation in the 1960s (Glaser \& Strauss, 1967; see also Charmaz, 2014; Corbin \& Strauss, 2008; Glaser, 2003; 2007). The philosophical paradigms underlying grounded theory are then described, and information of how those paradigms typically guide research practices in the field of social sciences is presented. Finally, criticisms that have been levelled against grounded theory are outlined so that $\mathrm{L} 2$ researchers are aware of limitations of this research methodology and, if possible, find a way to cope with those limitations when employing grounded theory in their studies or investigations.

\section{Grounded theory: A brief historical review}

Grounded theory was first formulated by Glaser and Strauss in the 1960s (Glaser \& Strauss, 1967) and constituted a reaction to theory-driven research methodologies (e.g., experiment or correlation) dominating the field of social sciences at that time. Glaser and Strauss (1967) argue that theory-driven research methodologies prove useful in the field of natural sciences; however, such methodologies offer very little for advancing the field of social sciences. One reason is because theory-driven research methodologies only aim at verifying or falsifying the truth of "grand theories", rather than generating new theories that can help explain continually emerging social phenomena. Furthermore, the focus of inquiry in the field of social sciences is fundamentally different from that in the field of natural sciences. That is, while the field of natural sciences (e.g., physics, chemistry, astronomy, etc.) are mainly concerned with studying natural phenomena that are governed by "natural forces", the field of social sciences (e.g., sociology, economics, education, etc.) are primarily concerned with studying social phenomena that are given rise by the interaction of human beings. Since human beings are endowed with "free will" or the capacity to act independently based on their own willingness, the use of theory-driven research methodologies can only provide partial insight into understanding complex social phenomena.

For instance, although theory-driven research methodologies are very useful for examining the relationship of two social phenomena (e.g., the relationship between social groups and educational achievement), such methodologies typically cannot provide deeper insight into why such a relationship exists (e.g., why and/or how social groups relate to educational achievement). Given such a limitation, Glaser and Strauss (1967) propose grounded theory as alternative methodology for advancing the field of social sciences. That is, unlike theory-driven research methodologies, grounded theory encourages data-driven research practices that potentially lead to theory construction to help explain why and/or how certain social phenomena occur.

It is worth noting, however, that although Glaser and Strauss initially shared the same perspective on how grounded theory should be implemented in research practices (Glaser \& Strauss, 1967), they eventually diverged in their perspectives, with Straus developing a specific model of grounded theory known as systematic design (Straus, 1987; Strauss \& Corbin, 1990), and Glaser developing another model of grounded theory known as emerging design (Glaser, 1992).

Although both systematic and emerging design have proved useful for studying social phenomena, these two designs have received a number of criticisms. One of the most wellknowns criticisms was put forward by Charmaz (1995) - who happened to be one of notable students of both Strauss and Glasser (Mills et al., 2006). According to Charmaz (1995, 
2000), systematic and emerging groundedtheory designs suffer from a major limitation. That is, these two grounded-theory designs emphasize data description rather than theoretical construction. Hence, important concepts that occur in the data will potentially be left unattended owing to heavy emphases on data description. To address this limitation, Charmaz $(1995,2000,2006,2014)$ proposes an alternative model of grounded theory widely known as constructivist grounded theory.

In the field of social sciences, constructivist grounded theory that Charmaz proposes has received wide attention in comparison to systematic and emerging grounded-theory designs. Furthermore, many researchers argue that the philosophical paradigms underlying constructivist grounded theory are more apparent than those underlying systematic and emerging grounded-theory designs (Mills et al., 2006). These philosophical paradigms that underlie the three groundedtheory designs are discussed in detail in the following section.

\section{Paradigms underlying systematic, emerging and constructivist grounded theory designs}

The three models of grounded theory (i.e., systematic, emerging and constructivist) similarly adhere to pragmatism and symbolic interactionism. These philosophical paradigms stand in contrast with the earlier philosophical paradigm dominating the field of socialscience research in the preceding years, namely, positivism.

Within the field of social science, 'positivism' refers to a philosophical paradigm which assumes that social phenomena (sic. 'reality') may be studied in objective ways (i.e., independent of individuals' perception, interpretation, or experience) by way of stringent data collection and analyses. In contrast, 'pragmatism' and 'symbolic interactionism' assume that it is implausible to study social phenomena in objective ways. Rather, an understanding of social phenomena emerges as researchers construct their own interpretations of the data they have collected (Clark et al, 2021; Guba \& Lincoln, 1994). Put another way, pragmatism and symbolic interactionism stipulate that data by themselves are meaningless entities, unless researchers attempt to connect the data with the context where they occur and construct the meaning based upon it.

$$
\text { Pragmatism and symbolic }
$$

interactionism further shape the underlying ontological and epistemological views of the three grounded-theory designs. Broadly define, ontological view refers to the view about the nature of social phenomena being investigated (Guba \& Lincoln, 1994, p. 108), while epistemological view refers to the view of how knowledge or understanding of social phenomena may be gained (Norton, 1999, p. 32). In the context of L2 education, such phenomena may be concerned with virtually all aspects pertaining to L2 educational practices. These include, for instance, students' (dis)engagement in L2 learning, teachers' professionalism, teachers' self-efficacy, L2 instructional materials, L2 education policy, classroom management, etc. With respect to the ontological view, therefore, the three groundedtheory designs predicate that those phenomena pertaining to L2 educational practices are constructed by participating individuals (e.g., students, teachers, stakeholders, etc.). Hence, with respect to their epistemological view, these three grounded-theory designs predicate that gaining an understanding of target phenomena involves (i) iterative process of investigating those phenomena as experienced or perceived by those participating individuals by way of carrying out interviews, observations, field notes, etc., and (ii) making judicious interpretations or good judgements based on relevant data that have been obtained. For this reason, all designs of grounded theory methodology do not discard researchers' personal values (i.e., subjective interpretations and good judgements) during the process of investigation. Rather, they afford strategies for researchers to make use of their personal values 
for the purpose of generating a comprehensive understanding of the phenomena under investigation (Clark et al., 2021; Norton, 1999). It is worth mentioning, however, that the ontological and epistemological views outlined in the preceding paragraph are more apparent in constructivist rather than in systematic and emerging grounded-theory designs. That is, there are discrepancies in the three groundedtheory designs as to how researchers should exert their personal values when attempting to generate an understanding of particular phenomena and construct theory to explain the phenomena being investigated.

For instance, while the emerging design maintains that researchers need to establish their understanding of the phenomena being studied based on the data they have obtained (Glaser, 1992), the constructivist design argues that drawing on personal values when examining available data can help researchers (i) gain deeper insight into the phenomena being investigated, and (ii) be able to construct a substantive theory to explain the target phenomena (Charmaz, 1995).

Furthermore, a heavier emphasis on data description during the whole process of investigation is much more apparent in Straus's systematic grounded-theory design. In fact, in his co-authored work with Juliet Corbin (Straus \& Corbin, 1990; Corbin \& Straus, 1990, 2008), Straus proposes "threetype coding" for the purpose of systematically describing and analyzing data that researchers have collected . Nonetheless, such a heavy emphasis on data description and analysis has received severe criticisms from both Glaser and Charmaz. In particular, Glaser (2003) argues that the use of three-type coding in systematic grounded-theory design can lead studies or investigations to be descriptive rather than theoretically sensitive. In the same vein, Charmaz (2014) notes that the threetype coding which Straus and Corbin (1990; Corbin \& Straus, 1990, 2008) propose changes grounded theory in fundamental ways. That is, such coding can turn grounded theory into analytical procedures and/or deemphasizes theoretical construction.

Despite this range of disagreements, all the proponents of grounded theory generally agree that grounded theory is not random research methodology. Rather, it follows well-planned procedures in the whole process of studies or investigations. These include theoretical coding, memo writing, theoretical sampling, process analysis, constant comparative analysis, theory saturation or theory construction (Charmaz, 2014; see also Clark et al., 2021; Creswell, 2012; Pandit, 1996). Indeed, these well-planned procedures constitute key features that distinguish grounded theory from other research methodologies in the field of social sciences. Such procedures are illustrated in Figure 1.

\section{Typical methodological procedures}

As illustrated in Figure 1, the first stage of grounded theory methodology (regardless of its design) starts with problem formulation and is followed by preliminary data collection. Following this, researchers analyze the preliminary data that they have collected by way of theoretical coding. In so doing, researchers classify and organize the data based on conceptual contents and categorical labels that emerge in given contexts. The purpose of theoretical coding at this initial stage of investigation is to generate important concepts and categories that can lead to the construction of tentative theory about a social phenomenon under investigation.

Following the construction of a tentative theory, researchers collect primary data to gain deeper insight into the nature of the phenomenon being investigated. To do so, researchers employ theoretical sampling to be able to select cases (or data) that can provide legitimate, credible, or trustworthy information about the phenomenon being investigated. Furthermore, researchers also engage in memo writing during the primary stage of data collection to gain a more comprehensive understanding about the phenomenon being 


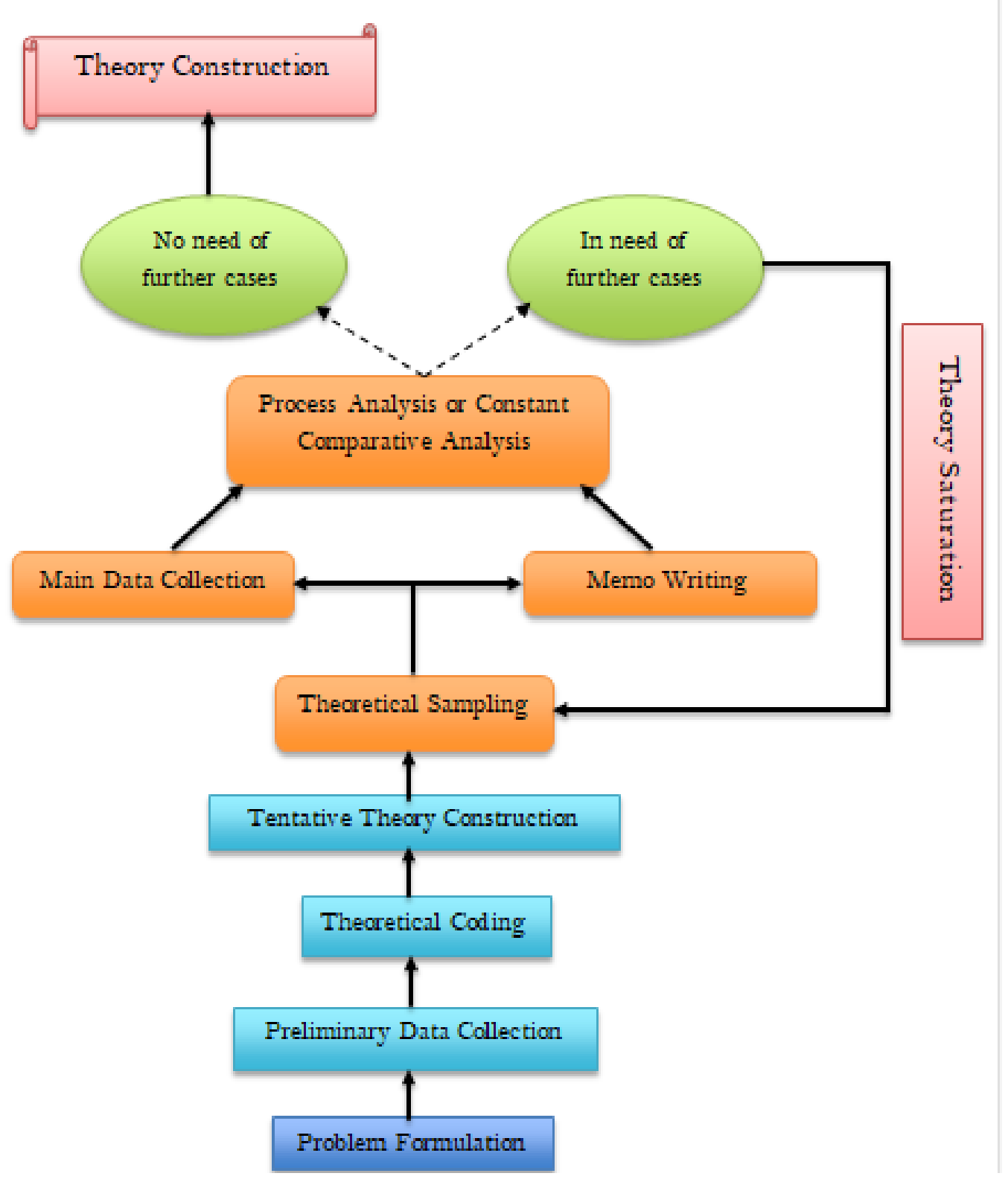

Figure 1. Typical methodological procedures of grounded theory

investigated. Indeed, memo writing can be very useful for providing additional information about the primary data being collected.

After researchers collect primary data, they then analyze the data through process analysis. That is, researchers examine sequence of cases manifested in the data that can be used to support or refine the tentative theory that has been previously constructed. More importantly, when analyzing such cases, researchers not only examine those cases that clearly support the tentative theory but also analyze those which appear conflicting. In the literature, this type of analysis is usually referred to as constant comparative analysis. The aim of performing a constant comparative analysis in grounded theory studies is, again, to support or refine the tentative theory previously constructed in the initial stage of investigation.

In the case where the results of constant comparative analysis still produce incomplete 
findings in that no definitive explanation can be drawn about the phenomena being investigated, researchers usually return to the field to collect more data. This iterative process of data collection (and, by implication, data analysis) is usually referred to as theory saturation. Furthermore, this iterative process continues until definitive explanation about the target phenomena can be reached. Researchers then conclude their investigation with theory construction after such a definitive explanation has been reached.

\section{Criticisms on grounded theory}

As noted in the beginning of this article, grounded theory constitutes one of prominent research methodologies in the field of social sciences. Nonetheless, the development of this research methodology has long been characterized by 'pros' and 'cons'. Bryman (2012) lists seven points of criticisms that have been levelled against grounded-theory designs. It is worth noting, however, that many of those criticisms listed in Bryman (2012) are not new. Rather, they represent those criticisms that have been put forward by the proponents of grounded theory i.e., Glaser, Straus, and Charmaz (see Paradigm ... section above for details). Relatively new criticisms that are listed in Bryman (2012) include the following:

(1) those theories generated in groundedtheory studies tend to be 'substantive' rather than 'formal'. As a result, the theories can only apply to restricted social phenomena;

(2) grounded theory does not clearly distinguish 'concepts' from 'categories'. Given that the notion of 'concepts' and 'categories' are critical in the process of data analysis in this research methodology, such a lack of clarity can make the practice of data analysis run the risk of being cyclical;

(3) theoretical coding in Straus's model of grounded theory tends to encourage fragmentation of data and, thus, can make important concepts and categories left unattended;

(4) with competing designs of grounded theory exist (systematic, emerging and constructivist), it is difficult to justify which design is best to apply and how to apply it.

\section{Conclusion}

This article has surveyed key literature on grounded theory and pointed out several strengths and limitations of the three grounded theory designs (systematic, emerging and constructivist). With respect to the strengths, it appears that any of the three groundedtheory designs might prove useful to be employed as research methodology in the field of social sciences, including L2 education (see e.g., Gan et al., [2004] and Liao \& Zhao [2012] for exemplary work). With respect to the limitations, researchers intending to employ grounded theory need to be aware of those criticisms that have been levelled against this research methodology and, where possible, find a way to address those criticisms. Indeed, the criticisms that have been levelled against grounded theory should not make researchers feel reluctant to employ this research methodology in their studies, especially when the research problem that they intend to address might be best approached or investigated using this research methodology.

\section{References}

Bryman, A. (2012). Social research methods (4th Ed.). Oxford: Oxford University Press.

Charmaz, K. (1995). Grounded theory. In J. Smith, R. Harré, \& L. Van Langenhove, L. (Eds.), Rethinking methods in psychology (pp. 27-49). London: Sage.

Charmaz, K. (2000). Grounded theory: Objectivist and constructivist methods. In N. Denzin \& Y. Lincoln (Eds.), Handbook of qualitative research (2nd ed., pp. 509-535). Thousand Oaks: Sage.

Charmaz, K. (2006). Constructing grounded theory: A practical guide through 
qualitative analysis. London: Sage.

Charmaz K. (2014). Constructing grounded theory. Thousand Oaks, CA: Sage.

Clark, T., Foster, L., Bryman, A., \& Sloan, L. (2021). Social research methods (6th Ed.). Oxford: Oxford University Press.

Corbin, J., \& Strauss, A. (1990). Grounded theory research: Procedures, canons and evaluative criteria. Qualitative sociology, 13(1), 3-21.

Corbin, J. \& Strauss, A. (2008). Basics of qualitative research: Techniques and procedures for developing grounded theory (3rd ed.). Thousand Oaks: Sage.

Creswell, J. (2012). Educational research: Planning, conducting, and evaluating quantitative and qualitative research (4th ed.). Boston: Pearson.

Hornberger, N., \& McKay, S. (Eds.). (2010). Sociolinguistics and language education. Bristol: Multilingual Matters.

Gan, Z., Humphreys, G., \& Hamp-Lyons, L. (2004). Understanding successful and unsuccessful EFL students in Chinese universities. The modern language journal, 88(2), 229-244.

Glaser, B. (1992). Basics of grounded theory analysis. Mill Valley: Sociology Press.

Glaser, B. (2003). Conceptualization contrasted with description. Mill Valley, CA: Sociology Press.

Glaser, B. (2007). Doing formal grounded theory: A proposal. Mill Valley, CA: Sociology Press.

Glaser, B. \& Strauss, A. (1967). The discovery of grounded theory. Chicago: Aldine.

Guba, E. \& Lincoln, Y. (1994). Competing paradigms in qualitative research. In N. Denzin \& Y. Lincoln (Eds.), Handbook of qualitative research (pp. 105-117). Thousand Oaks: Sage.

Liao, J., \& Zhao, D. (2012). Grounded theory approach to beginning teachers' perspectives of communicative language teaching practice. Electronic journal of foreign language teaching, 9(1), 76-90.

Mills, J., Bonner, A. \& Francis, K. (2006). The development of constructivist grounded theory. International journal of qualitative methods, 5(1), 25-35.

Norton, L. (1999). The philosophical bases of grounded theory and their implications for research practice. Nurse researcher, 7(1), 31-43.

Pandit, N. (1996). The creation of theory: A recent application of the grounded theory method. The qualitative report, 2(4), 1-15.

Strauss, A. (1987). Qualitative analysis for social scientists. New York: Cambridge University Press.

Strauss, A. \& Corbin, J. (1990). Basics of qualitative research: Grounded theory procedures and techniques. Newbury Park, CA: Sage. 